\title{
Introduction of Functionalism and Functional Translation Theory
}

\author{
Wang Zheng \\ Xiamen University Tan Kah Kee College
}

Keywords: functionalism, functional translation; theory

\begin{abstract}
From ancient times till now, there have been abundant findings from translation research in China, for instance, Yan Fu's “faithfulness, expressiveness and elegance”, Lu Xun's "Rather be faithful than smooth". The Chinese translation theories in the last century laid too much emphasis on literary translation. Textual features of pragmatic texts are greatly different from those of literary texts. As old translation theories do not suit the development of informative text translation, a new and effective theoretical tool-functional translation theory has attracted our attention in our search for an aid to explore the nature and special characteristics of pragmatic texts translation. Therefore, studying text translation in the light of functional translation theory should be of great help to translation practice. "Functionalism" means focusing on the function of texts and translation. Functionalism is a broad term for various theories that approach translation in this way. This thesis discusses the historic background and development of functional translation theory and some basic theories or concepts from functional translation theory, such as the Skopos theory, Nida's functional equivalence and Text typology and further explores their characteristics and significance to pragmatic translation.
\end{abstract}

\section{The Background and Development of Functionalism}

"Functionalism" means focusing on the function of texts and translation. Functionalism is a broad term for various theories that approach translation in this way. Functionalist approaches to translation were invented in the early twentieth century in Germany. In the following sections, the development and the historic background of functionalism will be discussed.

German functionalism plays a major role in the history of translation. But it did not appear overnight. Functionalist approaches to translation were developed in Germany by a number of German translators in the late1970s. However throughout its history, functionalism has its roots in early translation practice, especially in literary or Bible translation.

In the west, linguistics was a major discipline of the 1950s and 1960s. Therefore, it is hardly surprising that translation theories emphasizing linguistic equivalence were authoritative and exerted great influence at that time. Early translation theorists such as Cicero, Jerome and Martin Luther, all explained their difficulties in translation research. However, in the 1960s, due to the profound influence of the discipline of linguistics, translation study was regarded as a science and became linguistically oriented. Many definitions of translation emphasized the linguistic aspect. These definitions also shared something in common, i.e. viewing translation as a code-switching operation. (Newmark,1998:40)

Translating consists in reproducing in the receptor language the closest natural equivalent of the source-language message (Nida \& Taber, 1969:12). However in all countries, the criterion for translation is more concerned with word-for-word fidelity to the source text. For this equivalence-based approach, the emphasis is on the faithfulness or equivalence of the target text (TT) to the source text (ST). The original text has an absolute privilege over the translated text. Such a linguistic perspective undoubtedly had its merits. But at the same time, its demerits obvious reveal. In translation practice, it was found that there were cases when word-for-word fidelity to the source text was not desired. This is because translation is not strictly limited to linguistic points and the linguistic equivalence is often not a prerequisite for the translation of informative texts such as technical reports, news, business documents and instructions.

To sum up, such an equivalence-based linguistic approach still focuses on the source text, according to which the characteristics of the source text must be preserved in the target text and the 
target text must be equivalent to the source text. However, equivalence can not solve all the translation problems. In many translation efforts, translators encounter many cases in which functional matters take precedence over the normal standard of equivalence, especially at the information age beginning from the 1970s. Linguistics-oriented theorists did some adjustments in their own approaches, but seemed to cause more disorders. Thus, it was necessary to call for a new theory which could explore translation studies from an alternative perspective.

"The 1970s and 1980s saw a move away from the static linguistic typologies of translation shifts and the emergence and flourishing in Germany of a functionalist and communicative approach to the analysis of translation." (Munday, 2001:73) In translation practice, the strategy should not be determined by the text itself or the translator himself/herself, but should be mainly decided by the purpose of the translation. This purpose-oriented approach to translation is one of the central ideas of functionalist theory.

Functionalism is a broad term for various theories that approach translation in this way. Although what we call the Skopos theory has played a primary role in the development of this trend, a number of scholars subscribe to functionalism and draw inspiration from the Skopos theory without calling them anything like "Skopos". We shall thus be looking at functionalism as a broad approach, trying to distinguish between its parts wherever possible and necessary (Nord, 2001:1).From Nord's definition, we can see that functionalism is a broad term which pulls together a variety of functionalist approaches to translation. Functional translation approaches include not only the Skopos theory developed by German scholars, which have played a major role in studying translation, but also the theory of dynamic/functional equivalence put forward by American scholar Eugene A. Nida as well as English scholar Peter Newmark's text-type classifications and communicative vs. semantic translation. The reason why they are grouped together is that they all study translation theory and practice from the perspective of function or functions of texts, although they are somewhat different.

The background and the development of functional translation theory has been introduced in the previous section. In the following sections, some basic theories or concepts from functional translation theory will be introduced.

\section{Basic Theories or Concepts from Functional Translation Theory}

The Framework of the Skopos Theory. The Skopos theory, originating in Germany, has two major leading exponents, one was Hans J. Vermeer in an earlier time and the other was Christiane Nord, at the later time. "Skopos" is a Greek word for "purpose, intent, goal, aim and function". In Vermeer's point of view, any form of translational action must be conceived as an action and any action has an aim, a purpose. Skopos usually refers to the purpose of the target text. And Vermeer holds that the optimal strategies are decided by the Skopos or the translation purpose. (Vermeer, 1989:20)

It is quite different from equivalence-based theories, where the source text is absolutely the yardstick and equivalence is the top principle. In functional theories, what theorists most concerned about is the purpose or the effect of the target text.

There are three guiding rules in the Skopos theory: skopos rule, coherence rule and fidelity rule. The top-ranking rule for any translations is the 'Skopos rule', which says that a translational action is determined by its Skopos; that is, 'the end justifies the means' (Reiss and Vermeer, 1984:101).

It is not the source text that determines the translation process, but the prospective function or Skopos of the target text. This rule offers an answer to the question, that is, what is a good translation. Is it a free translation, a literal one or something else? It depends on the purpose or typology for which the translation is needed, because the Skopos of a particular translation task may require a 'free' or a 'faithful' translation, or anything between these two extremes. In informative text, "free form, but faithful content" is important because message or information is more important than the format.

Another important rule of the Skopos theory is the coherence rule. This rule specifies that a translation should be acceptable in the sense that it is coherent with the receivers' situation (Reiss 
and Vermeer, 1984:113). In other words In short, the target text should conform to the standard of intratextual coherence. It means translators should produce a text that is likely to be meaningful to the receiver of the target culture.

The third rule in the framework of the Skopos theory is the fidelity rule, or intertextual coherence' in Vermeer's words, referring to the faithfulness of the target text to the source text. Since a translation is an offer of information, it is expected to bear some kind of relationship with the corresponding source text. The translation should be a representation of the source text at least in one of the aspects of content, form or effect. The important point is that intertextual coherence should exist between source and target text, while the form it takes depends both on the translator's interpretation of the source text and on the translation Skopos. In informative texts translation is generally a representation of the content of the source text.

These three rules are ordered according to their importance. Intertextual coherence is considered subordinate to intratextual coherence, and both are subordinate to Skopos rule (Reiss and Vermeer, 1984:139). That is to say, the first concern of the translator is the purpose of a specific translation task rather than faithfulness to the source text. This is quite different from the other translation theories, which always advocate "faithfulness" and "equivalence".

Besides the three rules, there is another principle, "Function plus Loyalty", which is raised by Nord. Because the translation purpose of the translator may be in line with the intentions of the original author. What the translators should do is to show the responsibility, or "loyalty" towards those involved in translational interaction including the author, the translation initiator and the receiver. Loyalty commits the translator bilaterally to the source and the target sides. It must not be mixed up with fidelity or faithfulness, concepts that usually refer to a relationship between the source and the target texts. Loyalty is an interpersonal category referring to a social relationship between people. (Nord, 2001: 125)

Function refers to the factors that make a target text work in the intended way in the target situation. Loyalty refers to the interpersonal relationship between the translator, the source-text sender, the target-text addresses and the initiator (Nord, 2001:126). Nord believes that the translator should be responsible bilaterally for the target receiver as well as the original author. The translator should respect the source text producer and try to adjust the purpose of the target text and the source text writer's intentions.

The combination of function plus loyalty, makes a supplement principle that perfects the Skopos Theory, and grants the translator some liberty in the translating process in order to achieve the intended function of the target text, as well as keeping him from going far away from the original author's intention.

Based on the above introduction, we can have a general idea of the framework of the Skopos Theory. And through the great efforts made by Vermeer, Nord and other translation researchers, the Skopos Theory is still very influential in Germany and has been spread to other parts of the world, including China.

Nida's Functional Equivalence. Eugene Nida, a famous American translation theorist and a Bible translator, also exerts a profound influence on the worldwide translation field. As opposed to the traditional conception of linguistic equivalence, Nida takes a functional approach to translation but distinguishes formal and dynamic equivalence in translation. "Formal equivalence" refers to faithful reproduction of the source text in terms of the formal elements and "dynamic equivalence" denotes acquisition of equivalent extra-linguistic communicative effect. Viewing translating as communicating, he advocates dynamic equivalence as a translation criterion.

Nida explains his concept of dynamic equivalence in the following way: "dynamic equivalence is there to be defined in terms of the degree to which the receptors of the message in the receptor language respond to it in substantially the same manner as the receptor in the source language. This response can never be identical, for the cultural and historical settings are too different, but there should be a high degree of equivalence of response, or the translation will have failed to accomplish its purpose." (Nida \& Taber, 2004:24).

He emphasizes that the target text should function in the same manner in the target situation as 
the source text functions in the source context. That is to say, the target text should be functionally equivalent to the source text. Later, Nida employs the term "functional equivalence" to replace the often misunderstood "dynamic equivalence" to emphasize the concept of function as well as to provide a much sounder basis for talking about translation as a form of communication since the focus is on what a translation does or performs (Nida, 1993:91). "Functional equivalence" highlights the concept of "function" in Nida's theory.

We can see that dynamic equivalence focuses on producing the equivalent effect of the message upon the receiver. In Nida's point of view, when determining whether a translation is faithful to the original text or not, the critic should not compare the formal structure between the source text and the translated one, but comparing “receptors' response”. He holds that if a close, formal translation is likely to result in misunderstanding of the source text, make no sense, or pose great difficulty in understanding, the translator is supposed to adjust the original text in order to make the text of translation understandable and acceptable to readers and to achieve the intended response. The adjustments may be on all levels: phonology, lexicon, syntax, and discourse. Usually, the greater the difference between the source and target languages, the greater the need for adjustments and the greater the differences between the source and target cultures, the greater the need for adjustments (Nida, 1993:91)

Nida has played a key role in shifting away from strict word-for-word equivalence. His emphasis on reader's response and his idea of adjusting the original text to make the translation understandable and acceptable to the target readers shed much light on practical translation.

Later on, Nida changed "dynamic equivalence" into "functional equivalence", because it seemed much more satisfactory to use the expression "functional equivalence" in describing the degree of adequacy of a translation.

Text Typology and Translation Methods. There are two famous theorists of Functionalism who made a major contribution to the theory of text typology: Katherina Reiss and Peter Newmark. Text typology is a very useful tool to explore translation approaches for different types of text. In this thesis, the author will focus on the translation of informative texts. (Newmark, 2006: 39).

According to functionalist approaches, it is the intended purpose or function of the target text that determines the translation method. This means that the translator needs to determine the translation purpose first, and next whether the translation intended to show the different aspects of the source text or to achieve the same functions as the original text. Lastly, the translator must then decide the suitable translation strategies and methods.

Text type and genre are used to refer to a distinctive category of discourse of any type, spoken or written, with and without literary aspiration. Text type as an essential pattern of text embodies linguistic functions, thinking modes and cultural conventions. The study of text types in the text-oriented translation will help the translator to have a thorough understanding of the text and to obtain adequate equivalence in target language text from the source language text. Every text is characterized by one or several basic communication functions. Different text type should require different transfer methods (Reiss, 1989:112). When a lot of pragmatic texts, science and technology texts appeared in the translation areas, the interrelation between the text type and transfer method began to arouse the interest of translation scholars. Many translation scholars presented the concept of standards for classifying the correlation between the text type and translation method. The theories concerning text type and translation are mostly on the model of language functions proposed by Peter Newmark and Katharina Reiss. (Newmark, 1998:41).

\section{Conclusion}

To sum up, functional translation theory was created since traditional translation theories are not so suitable for the translation of pragmatic texts, such as technical text, instruction, and so on, which has for a long time been ignored by literary translation researchers. The input from functionalist endeavor will certainly give an impetus to the academic development of translation practice. In functionalism, the translation strategy should not be determined by the text itself or the translator himself/herself, but should be mainly decided by the purpose of the translation and the function of 
texts and translation.

This purpose-oriented approach to translation is one of the central ideas of functionalist theory. Functionalism is a broad term for various theories that approach translation in this way, such as the Scopos, Nida's functional equivalence and text typology. In addition, for the limited pages in the thesis, the author cannot present all the characteristics theories of functional translation strategies in details. Those who show interest in functionalism may further probe into more effective strategies and approaches under functionalism.

\section{Reference}

[1] Munday, Jeremy. Introducing Translation Studies: Theories and Application [M]. London: Routledge, 2001.

[2] Newmark, P. A Textbook of Translation [M]. New York: Prentice Hall International, 1988.

[3] Newmark P. 1998. More Paragraphs on Translation [M]. Multilingual Matters Limited.1998.

[4] Newmark, P. (2006). About Translation [M]. Beijing: Foreign Language Teaching and Research Press.

[5] Nida, E. A. and Taber, C. R. The Theory and Practice of Translation [M]. Leiden: The Netherlands, 1964.

[7] Nord, C. Text Analysis in Translation: Theory, Methodology and Didactic Application of a Model for Translation-Oriented Text Analysis [M]. Amsterdam: Rodopi, 1991.

[8] Nord, C. Translating as a Purposeful Activity-Functional Approaches Explained [M]. Shanghai: Shanghai Foreign Language Education Press, 1997.

[9] Nord, C. A Functional Typology of Translation [M]. Amsterdam, 1997.

[10] Reiss, K. and Vermeer H. J. General Foundations of Translation Theory [M]. Tubingen: Niemeyer, 1984.

[11] Reiss, K. Text types, translation types and translation assessment. In: Chesterman, A. (ed.) (1989). Readings in Translation Theory.

[12] Vermeer, H.J. Skopos and Translation Commission [M]. Heidelberg: Universitat, 1989. 